\title{
Smoldering Combustion of Horizontally Oriented Polyurethane Foam with Controlled Air Supply
}

\author{
LEI PENG, CHANG LU, JIANJUN ZHOU, LINHE ZHANG, and FEI YOU \\ State Key Laboratory of Fire Science, USTC \\ Hefei Anhui, 230026
}

\begin{abstract}
An experimental and theoretical study on smoldering combustion of the flexible polyurethane foam is presented. The experiments are conducted in a small scale and horizontally oriented combustion chamber with a forced forward air flow through the foam. The air flux is controlled by a flow meter. Temperature histories during the smoldering combustion are measured by the thermocouples to probe the structure of the smoldering process and to calculate the smoldering propagation velocity. The results show the increasing air supply contributes to both enhance the oxidation reaction and increase the heat loss. The integral method is employed to develop the theoretical model of the one-dimensional forward smolder. Comparison is made between the model and the experimental results and shows a good agreement.
\end{abstract}

KEYWORDS: flexible polyurethane foam, smoldering combustion, smoldering propagation, integral model

\section{NOMENCLATURE LISTING}

\begin{tabular}{|c|c|c|c|}
\hline c & heat capacity $(\mathrm{kJ} / \mathrm{kgK})$ & Greek & \\
\hline$H$ & $\begin{array}{l}\text { heat release of reaction per unit } \\
\text { mass solid }(\mathrm{kJ} / \mathrm{kg})\end{array}$ & $\begin{array}{l}\alpha \\
\beta_{1,2}\end{array}$ & $\begin{array}{l}\text { ratio of oxidative reaction solid } \\
\text { temporary symbols }\end{array}$ \\
\hline$k$ & thermal conductivity(W/mK) & $\mu_{a, b}$ & temporary symbols \\
\hline$\dot{m}^{\prime \prime}$ & mass flux(kg/s) & $r$ & stoichiometric coefficient \\
\hline & heat flux released per mass & $\delta$ & thermal thickness(m) \\
\hline$\dot{q}^{\prime \prime}$ & $\operatorname{solid}(\mathrm{kJ} / \mathrm{kg})$ & $\varphi$ & porosity \\
\hline$t$ & time(s) & $\rho$ & $\operatorname{density}\left(\mathrm{m}^{3} / \mathrm{s}\right)$ \\
\hline$T$ & temperature(K) & subscripts & \\
\hline Ts & smolder temperature(K) & 0 & initial \\
\hline$u$ & air velocity $(\mathrm{m} / \mathrm{s})$ & A & air \\
\hline$v_{s}$ & smoldering velocity(m/s) & $c$ & char \\
\hline$x$ & coordinate(m) & $\mathrm{O}_{2}$ & oxygen \\
\hline Y & mass fraction & $p$ & pyrolysis \\
\hline
\end{tabular}

\section{INTRODUCTION}

Smoldering combustion is a non-flaming, self-sustaining, propagating, heterogeneous reaction in the porous combustible materials [1]. To sustain the reaction, enough heat derived from the exothermic reactions and enough oxygen transported from outside are needed. Smoldering is significant in fire safety is because it produces a great amount of toxic gases than does flaming and it can lead to the initiation of a flaming fire through the 
transition from smoldering. Smoldering combustion occurs typically in the permeable materials such as cotton, cigarette, underground coal and polyurethane foam.

The mechanism of smoldering combustion involves complex physical and chemical processes. A number of researchers [1-8] have done some work to understand the propagation and extinguishing process of smoldering combustion. Ohlemiller [1] studied the chemistry and heat transfer involved in sustained smolder propagation, and developed a general model of propagation processes. Ohlemiller and Lucca [2] experimented and compared the characteristics of opposed and forward smolder. Two different reactions were founded in forward smolder, a nonoxidative pyrolysis reaction and a oxidation of the residue chars. Dosanjh and Pagni [3,4] developed a model of smolder including two reaction zones: a nonoxidative pyrolysis reaction and a char oxidative reaction. Schult $[5,6]$ used large activation energy asymptotic methods to study the structure and the propagation of smolder wave. Torero $[7,8]$ experimentally studied the vertical smolder of polyurethane foam considering the buoyancy effect, and employed Dosanjh's theoretical model to correlate the experimental data.

The experimental results in literatures show that the oxygen supply plays a very important role in the smoldering combustion processes. In this paper, horizontally forwarded smoldering combustion of polyurethane foam with controlled oxygen supply is examined to further understand the characteristics of smoldering propagation. A theoretical model is developed using the heat-balance integral method $[9,10]$. Results are compared with experimental data.

\section{EXPERIMENTAL SETUP}

The experiment configuration is shown in Fig. 1. The smolder experiments are conducted in a horizontal stainless steel container. The porous material used in the experiments is open-cell flexible polyurethane foam, with $26.5 \mathrm{~kg} / \mathrm{m} 3$ density and 0.975 porosity. The cross section of the foam sample is $0.15 \mathrm{~m} \times 0.16 \mathrm{~m}$ at $0.20 \mathrm{~m}$ long. Insulation material (aluminum silicate) is filled tightly between the walls and the sample to minimize heat losses and to prevent preferential flow of gas through edges of the sample. An electrically heated igniter is placed in contact with the foam at one side of the sample to heat up the foam and initiate the combustion. The igniter is connected to AC transformer, whose voltage can be adjusted. The ignition power in our experiments is $84 \mathrm{~W}$ and applied for $780 \mathrm{~s}$. The temperature of the foam during smoldering processes is measured by an array of K-type thermocouples (1mm diameter stainless steel sheath), which are embedded along the centerline of the foam, and the distance between two adjacent thermocouples is $3 \mathrm{~cm}$. The gas flow rate is measured and controlled with a controlled flow meter. It is actively controlled in the experiments because the pressure losses across the sample decrease as the smolder reaction propagates along the sample. The thermocouples were linked to A/D conversion, and recorded onto a computer. 


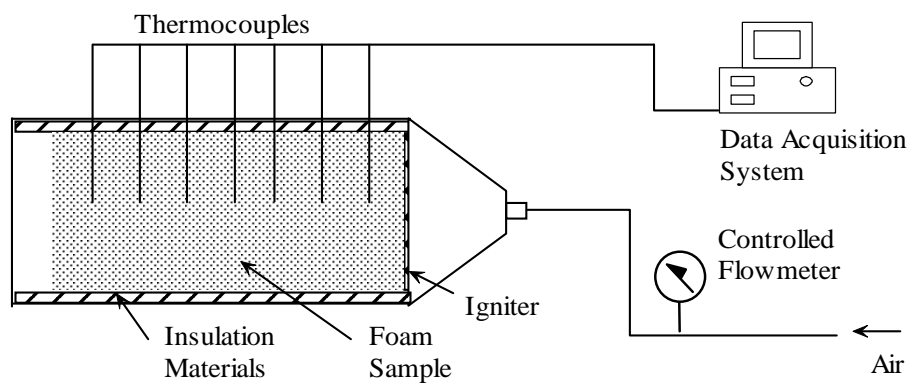

Fig. 1. Schematic of experimental setup.

\section{EXPERIMENTAL RESULTS}

Experiments are performed at several forward air fluxes to determine the effect of the oxygen supply. Figure 2 shows the foam sample after smoldering combustion with oxygen flux at $0.1 \mathrm{~m}^{3} / \mathrm{h}$. It is observed that the foam approximately retains its integrity during the smoldering experiment.

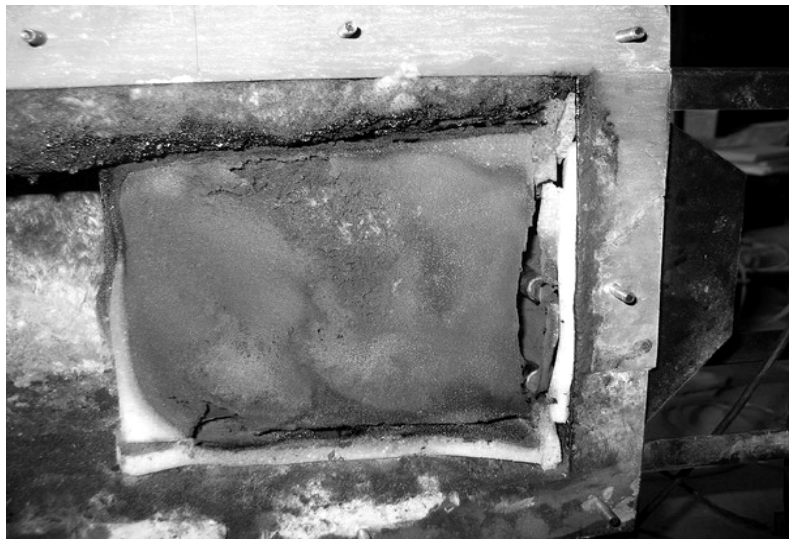

Fig. 2. Foam sample after smoldering process.

Typical temperature histories of the foam sample during the smolder at an oxygen flux of $0.06 \mathrm{~m}^{3} / \mathrm{h}$ are presented in Fig. 3a and $\mathrm{b}$. The general characters of the smolder propagation process are shown in the Fig. 3a. When the smolder reaction region approaches the thermocouple location, the foam temperature increases rapidly due to the heat transfer form the reaction region. When its temperature reaches a high enough value, the reaction of the foam starts and provides the heat to the foam ahead. After reaching a maximum, the temperature starts to decrease rather sharply because of the cooling of the forced fresh air. It is somewhat different from the vertical smoldering experiments by Torero [8], who observed that the maximum temperature remained almost constant after the reaction region passed through the foam. Figure $3 \mathrm{~b}$ shows the temperature profiles along the foam with increasing time. 

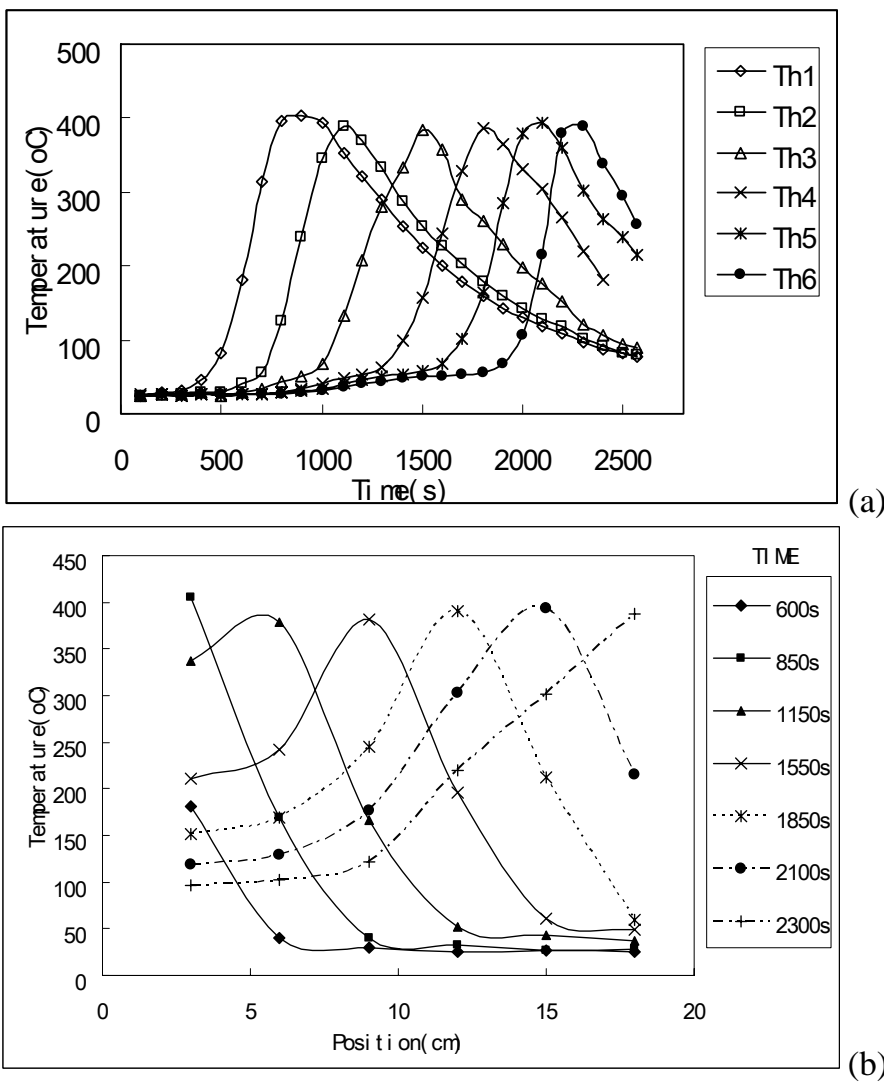

Fig. 3a. Temperature histories of the foam sample, b. Temperature profiles along the foam with time. The oxygen flux is $0.06 \mathrm{~m}^{3} / \mathrm{h}$.

The distance of the two thermocouples is known, so the smoldering propagation velocity is calculated from the temperature histories of the thermocouples via two special thermocouples and the time interval between its isotherms. Figure 4a shows the smoldering propagation velocity along the foam sample in several oxygen fluxes. The smolder velocity along the foam remains almost constant during the smoldering process. It is seen in Fig. 4b that the smoldering velocity (average velocity alone the sample) increases firstly with the air supply. When the oxygen flux reaches about $0.11 \mathrm{~m} 3 / \mathrm{h}$, a maximum smoldering velocity is presented. It is the result of the balance between the heat release of the exothermic oxidation reaction and the heat transfer from reaction region to the surroundings. 

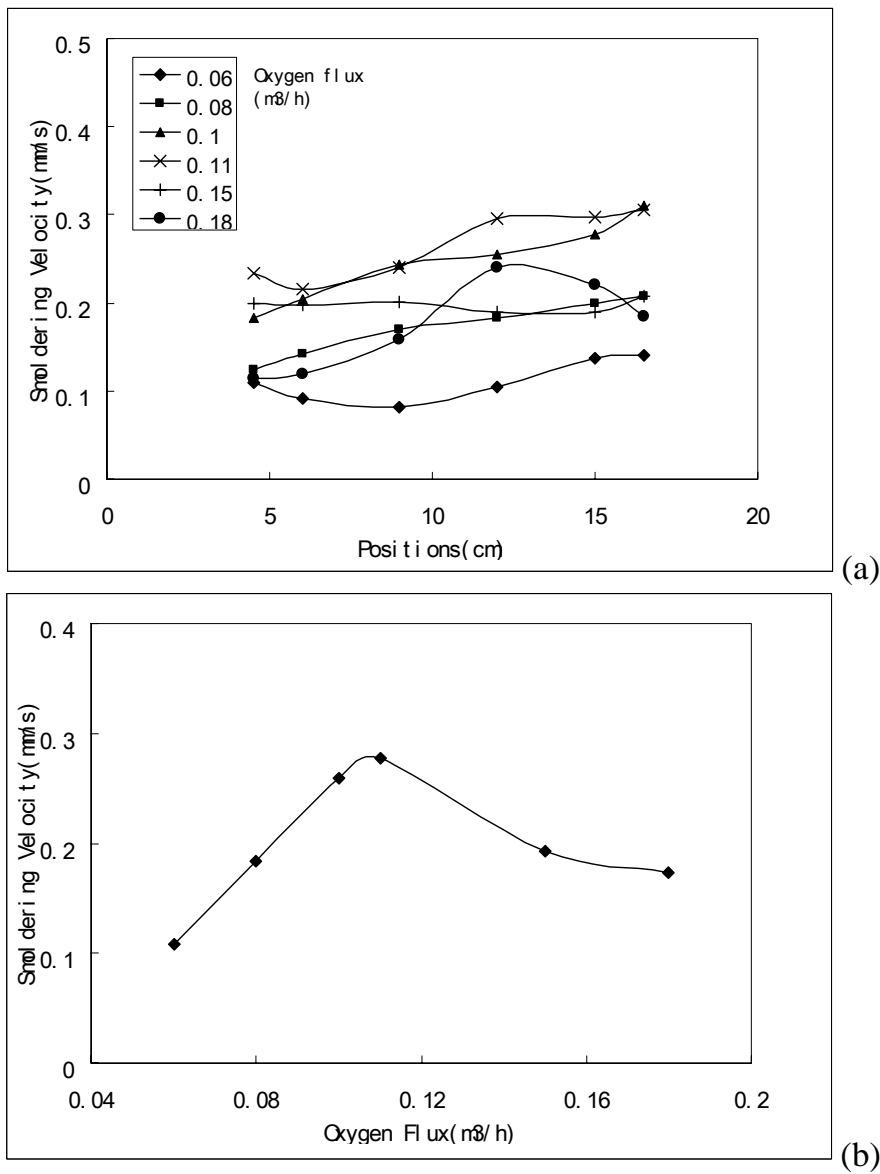

Fig. 4a. Smolder velocity in several oxygen fluxes along the foam sample; b. Average smolder velocity of the foam with increasing oxygen flux.

\section{SMOLDERING MODEL}

In this paper, smoldering is assumed to be one-dimensional and remains steady propagation. We divide the one-dimensional smoldering configuration into four regions by its physical and chemical characters (Schematic is shown in Fig. 5),

(1) Virgin material region without heating up, $x>x_{0}, T=T_{0}$;

(2) Heated virgin material region without pyrolysis, $x_{0}<x<x_{p}$, the solid properties are unaltered;

(3) Reaction region, $x_{p}<x<x_{c}$, pyrolysis and oxidation reaction occur in this region;

(4) Residual char and ash region with lower temperature, it is an unreactive region. 


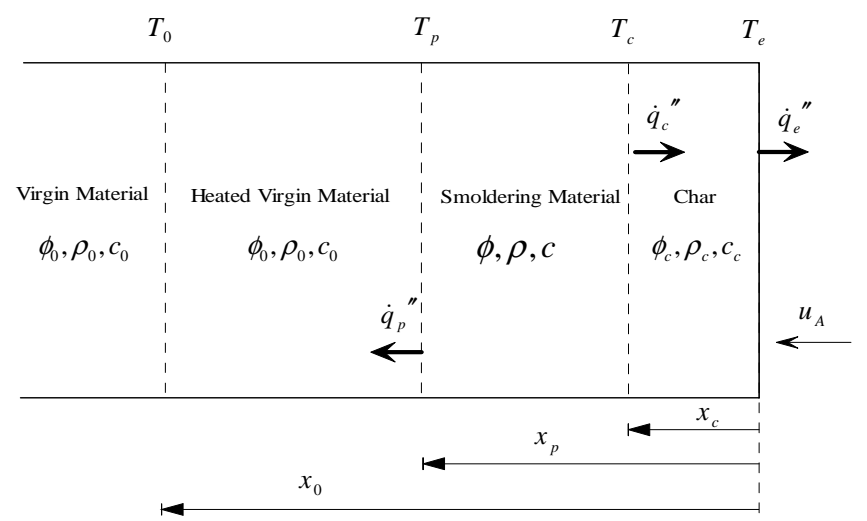

Fig. 5. Schematic of the one-dimensional forward smolder.

The detailed chemistry of smolder is complicated. It is usually thought that the reaction can be described by a three-step reaction model given by Roger and Ohlemiller [11]: (1) Endothermic pyrolysis of the material, (2) Exothermic oxidative decomposition of the material, (3) Exothermic oxidation of the char. The char is not totally consumed by the oxidizer since char require more conditions of oxygen supply and temperature for the oxidation. We assume the material oxidation and char oxidation to be a one-step reaction and the residual char is unreactive. Therefore, the reaction model used in this paper is expressed as:

Fuel $+Q_{1} \rightarrow$ Char + Gases

Fuel $+\mathrm{O}_{2} \rightarrow$ Char + Gases $+Q_{2}$

Since smoldering combustion is generally oxygen limited, all oxygen is assumed to be consumed by the reaction. In our model, the material is assumed to be continuous with constant density and porosity. The thermal properties are assumed to be constant. The gas and solid are assumed to be in local thermal equilibrium. We assume the activity energy in the smoldering region is high enough to regard the reaction zone to be very thin compared to the length of the material. Thus the smoldering reaction region can be considered to be a plane $\left(x_{p}=x_{c}\right)$. The temperature of the reaction plane is assumed

as $T_{s}$, the smolder temperature. 


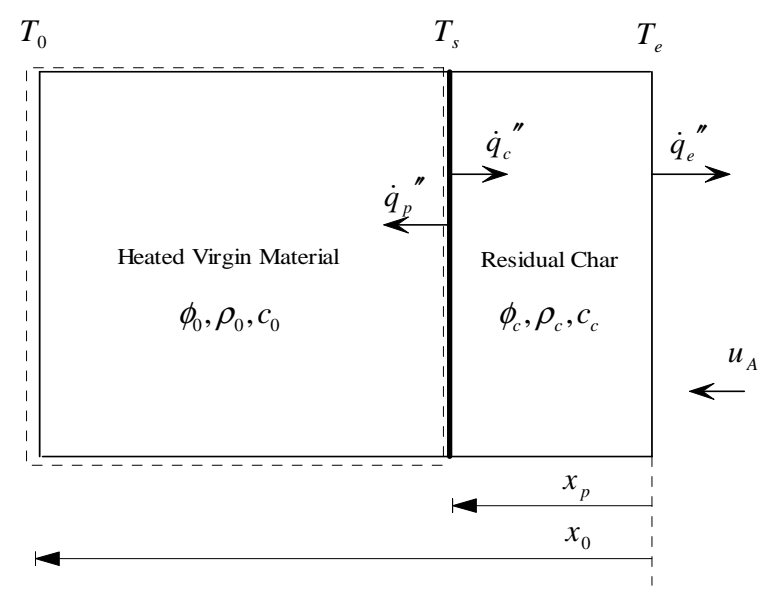

Fig. 6. Schematic of the heated virgin region.

Firstly, consider the heated virgin material region. Figure 6 shows the control volume of this region. The temperature profile in this region is assumed as:

$T(x, t)=a(t)+b(t) x+c(t) x^{2}$

and the boundary conditions are:

$T\left(x_{0}\right)=T_{0},\left.\quad \frac{\partial T}{\partial x}\right|_{x=x_{0}}=0, \quad T\left(x_{p}\right)=T_{s}$

where $k_{0}$ is the effective thermal conductivity $k_{0}=\phi k_{A}+(1-\phi) k_{F}$ and $\dot{q}_{p}^{\prime \prime}$ is the heat flux into the virgin region $\dot{q}_{p}^{\prime \prime}=-\left.k_{0} \frac{\partial T}{\partial x}\right|_{x=x_{p}}$.

Obtaining the temperature profile from Eq. 1 and boundary conditions Eq. 2:

$T(x, t)=T_{0}+\frac{T_{s}-T_{0}}{\left(x_{p}-x_{0}\right)^{2}}\left(x-x_{0}\right)^{2}$

The conservation equation of energy in this region is expressed as:

$\left[\phi \rho_{A}^{\prime} c_{A}+(1-\phi) \rho_{0} c_{0}\right] \frac{d}{d t} \int_{x_{p}(t)}^{x_{0}(t)} T(x) d x=$

$\dot{q}_{p}^{\prime \prime}+\left[(1-\phi) \rho_{0} c_{0}+\phi \rho_{A}^{\prime} c_{A}\right]\left[T_{0} \frac{d x_{0}(t)}{d t}-T_{s} \frac{d x_{p}(t)}{d t}\right]+\phi \rho_{A}^{\prime} c_{A} u_{A}\left(T_{s}-T_{0}\right)$

where $\rho_{A}^{\prime}$ is the density of the gas after the smoldering reaction.

Applying the temperature profile (Eq. 3 ) and integrating from $X_{p}$ to $X_{0}$ provides: 
$\frac{1}{3} \frac{d x_{0}}{d t}+\frac{2}{3} \frac{d x_{p}}{d t}=\frac{2 k_{0}}{\left[\phi \rho_{A}^{\prime} c_{A}+(1-\phi) \rho_{0} c_{0}\right]} \frac{1}{x_{0}-x_{p}}+\frac{u_{A} \phi_{0} \rho_{A}^{\prime} c_{A}}{\left[\phi \rho_{A}^{\prime} c_{A}+(1-\phi) \rho_{0} c_{0}\right]}$

Next consider the mass balance and the energy balance in the reaction region. The smoldering velocity $v_{s}$ is equivalent to $\frac{d x_{p}}{d t}$. The reaction mass rate of the fuel is given as $\rho_{0} \frac{d x_{p}}{d t}$. We assume that the ratio $\alpha$ of the fuel takes part in the oxidative reaction, while the other $(1-\alpha)$ takes part in the nonoxidative pyrolysis reaction. As a plane, the conservation equations of mass and energy in the reaction zone are expressed as:

$\alpha \gamma \rho_{0} \frac{d x_{p}}{d t}=\dot{m}_{o_{2}}^{\prime \prime}$

$(1-\phi) \rho_{0} v+\dot{m}_{A}^{\prime \prime}=\left(1-\phi_{c}\right) \rho_{c} v+\phi_{c} \rho_{A}^{\prime} u$

$\alpha \rho_{0} \frac{d x_{p}}{d t} H_{2}-(1-\alpha) \frac{d x_{p}}{d t} \rho_{0} H_{1}=\dot{q}_{p}^{\prime \prime}+\dot{q}_{c}^{\prime \prime}$

where the air mass flux is given by $\dot{m}_{A}^{\prime \prime}=\phi \rho_{A} u$, and the oxygen mass flux is given by $\dot{m}_{o_{2}}^{\prime \prime}=Y_{O_{2}} \phi \rho_{A} u \cdot \gamma$ is the stoichiometric coefficient oxygen/solid. $\mathrm{H}_{2}$ is the heat of oxidation reaction per unit mass sample for smolder, and $\mathrm{H}_{1}$ is the heat of pyrolysis per unit mass sample.

Finally consider the region of residual char. We assume this residual layer is unreactive and the char porosity is the same as the material. Also, the temperature profile is assumed as:

$T(x, t)=a(t)+b(t) x+c(t) x^{2}$

With the assumption of steady smoldering propagation, we neglect heat losses to the environment from char surface. Using the boundary conditions:

$T(x=0)=T_{0}, T\left(x_{c}\right)=T_{s}, \dot{q}_{e}^{\prime \prime}=0$

yields the temperature profile:

$T(x, t)=T_{0}+\frac{T_{p}-T_{0}}{\left(x_{p}-x_{0}\right)^{2}}\left(x-x_{0}\right)^{2}$

The conservation equation of energy is expressed as: 


$$
\begin{aligned}
& {\left[\phi \rho_{A} c_{A}+(1-\phi) \rho_{c} c_{c}\right] \frac{d}{d t} \int_{0}^{x_{c}} T d x} \\
& =\left[\phi \rho_{A} c_{A}+(1-\phi) \rho_{c} c_{c}\right] T_{s} \frac{d x_{c}}{d t}+u_{A} \phi \rho_{A} c_{A}\left(T_{0}-T_{s}\right)+\dot{q}_{c}^{\prime \prime}
\end{aligned}
$$

Substituting Eq. 11 into the above equation and simplifying it reduces to

$\left[\phi \rho_{A} c_{A}+(1-\phi) \rho_{c} c_{c}\right] \frac{2\left(T_{0}-T_{s}\right)}{3} \frac{d x_{c}}{d t}=\frac{2 k_{c}}{x_{c}}\left(T_{s}-T_{0}\right)+u_{A} \phi \rho_{A} c_{A}\left(T_{0}-T_{s}\right)$

According to the analysis above, we develop the mathematical equations of the forced forward smolder:

$\alpha \gamma \rho_{0} \frac{d \delta_{c}}{d t}=\dot{m}_{o_{2}}^{\prime \prime}$

$\left[\alpha H_{2}-(1-\alpha) H_{1}\right] \frac{d \delta_{c}}{d t} \rho_{0}=2 k_{0} \frac{T_{s}-T_{0}}{\delta_{0}}+2 k_{c} \frac{T_{s}-T_{0}}{\delta_{c}}$

$(1-\phi) \rho_{c} c_{c} \frac{2}{3} \frac{d \delta_{c}}{d t}=\frac{2 k_{c}}{\delta_{c}}+\dot{m}_{O_{2}}^{\prime \prime} c_{A} / Y_{O_{2}}$

$(1-\phi) \rho_{0} c_{0}\left[\frac{1}{3} \frac{d \delta_{0}}{d t}+\frac{d \delta_{c}}{d t}\right]=\frac{2 k_{0}}{\delta_{0}}+\left[(1-\phi) \rho_{0}-(1-\phi) \rho_{c}\right] c_{A} \frac{d \delta_{c}}{d t}+\dot{m}_{O_{2}}^{\prime \prime} c_{A} / Y_{O_{2}}$

where $\delta_{0}=x_{0}-x_{p}$ is the thermal penetration, $\delta_{c}=x_{p}$ is the char layer thickness, and then the smoldering velocity is equal to $\frac{d \delta_{c}}{d t}$. The smoldering temperature $T_{s}$ is obtained from the experiments results. Substituting Eqs. 14, 15, 16 into Eq. 17 yields:

$\frac{1}{3} \frac{d \delta_{0}}{d t}=\frac{1}{\delta_{0}} \beta_{1}-\beta_{2}$

Where

$\beta_{1}=\frac{2 k_{0}}{(1-\phi) \rho_{0} c_{0}}\left(1+\frac{\left(T_{s}-T_{0}\right)\left(\rho_{0} c_{0}+\rho_{c} c_{A}-\rho_{0} c_{A}\right)}{H_{1} \rho_{0}+\frac{2}{3}(1-\phi) \rho_{c} c_{c}\left(T_{s}-T_{0}\right)}\right)$, and 
$\beta_{2}=\frac{(1-\phi)\left[\frac{\left(H_{1}+H_{2}\right) \dot{m}_{O_{2}}^{\prime \prime}}{\gamma}+\frac{c_{A}\left(T_{s}-T_{0}\right) \dot{m}_{O_{2}}^{\prime \prime}}{Y_{O_{2}}}\right]}{H_{1} \rho_{0}+\frac{2}{3}(1-\phi) \rho_{c} c_{c}\left(T_{s}-T_{0}\right)}-\frac{c_{A} \dot{m}_{O_{2}}^{\prime \prime}}{Y_{O_{2}}}$

In steady smolder with controlled air supply, the smoldering propagation velocity is constant and the smoldering wave structure remains steady. Therefore, the value of the thermal penetration of the foam $\delta_{0}$ is regarded as a constant, $\frac{d \delta_{0}}{d t}=0$. So we can calculate the smoldering propagation velocity $v_{s}$ by the following equation:

$v_{s}=\frac{d \delta_{c}}{d t}=\frac{1}{(1-\phi)\left(\rho_{0} c_{0}+\rho_{c} c_{A}-\rho_{0} c_{A}\right)}\left[\frac{2 k_{0} \beta_{2}}{\beta_{1}}+\frac{\dot{m}_{O_{2}}^{\prime \prime} c_{A}}{Y_{O_{2}}}\right]$

We choose property values to calculate the smoldering velocity of the polyurethane foam in order to compare to our experimental results. The properties used in the calculation are obtained from literature $[8,12]$ and the experimental data:

$$
\begin{aligned}
& \rho_{0}=26.5 \mathrm{~kg} / \mathrm{m}^{3}, c_{0}=1.700 \mathrm{~kJ} / \mathrm{kgK}, k_{0}=0.081 \mathrm{~W} / \mathrm{mK}, \phi=0.975, \\
& \rho_{A}=1.225 \mathrm{~kg} / \mathrm{m}^{3}, c_{A}=1.088 \mathrm{~kJ} / \mathrm{kgK}, \rho_{c}=10 \mathrm{~kg} / \mathrm{m}^{3}, c_{c}=1.1 \mathrm{~kJ} / \mathrm{kgK}, \\
& H_{1}=570 \mathrm{~kJ} / \mathrm{kg}, H_{2}=5700 \mathrm{~kJ} / \mathrm{kg}, \gamma=0.68, Y_{O_{2}}=0.23, T_{0}=298 K
\end{aligned}
$$

The ratio of the experimental and calculated smoldering velocity for different oxygen fluxes is presented in Fig. 7. It shows that Eq. 19 predicts well the smoldering velocity for the oxygen flux lower than $0.11 \mathrm{~m}^{3} / \mathrm{h}$. For the oxygen flux higher than $0.11 \mathrm{~m}^{3} / \mathrm{h}$, the experimental smoldering velocities are lower than the theoretically predicted velocities. It is understandable, since some oxygen would move through the foam sample without reaction for higher air flow rate; however we assume that all oxygen is consumed by the reaction.

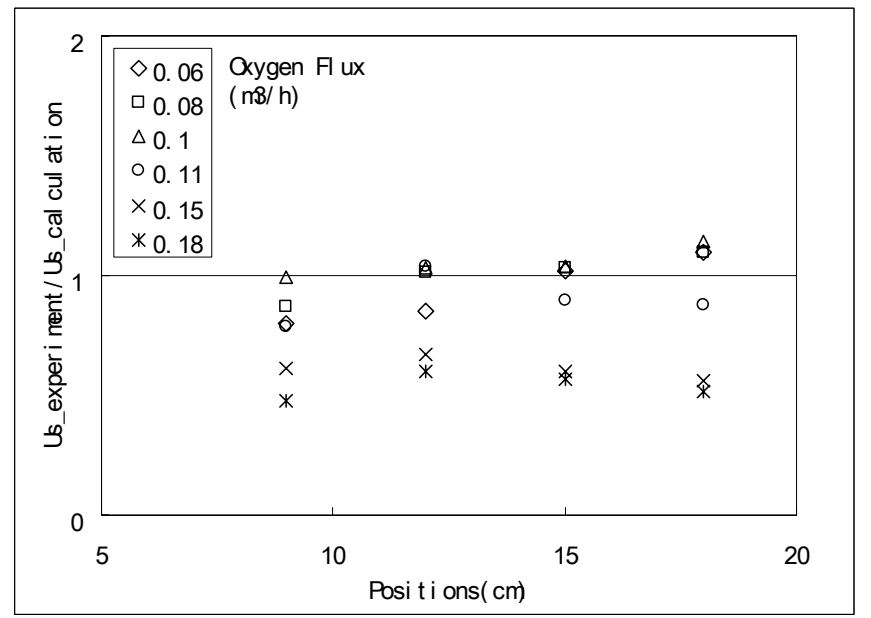

Fig. 7. Correlation of the experimental and calculated smoldering velocity from the model for several oxygen fluxes along the foam sample. 
To correct Eq. 19, we define a modified oxygen flux $\dot{m}_{\mathrm{O}_{2}}^{\prime \prime}=(1-\mu) Y_{\mathrm{O}_{2}} \phi \rho_{A} u_{A}$ for the oxygen flux higher than $0.11 \mathrm{~m}^{3} / \mathrm{h} . \mu=\mu\left(u_{A}\right)$ relates to air flow velocity $u_{A}$ and is assumed to be linear function with $u_{A}$ for simplicity such that:

$\mu=\mu_{a} u_{A}+\mu_{b}$

In this work $\mu_{a}$ and $\mu_{b}$ will be selected such the correlation of the data with Eq. 19 is optimized.

The results of the correlation of the average smoldering velocity as a function of oxygen flux are presented in Fig. 8. It shows that a good correlation of the smoldering velocities between modified model calculation and experimental measurement.

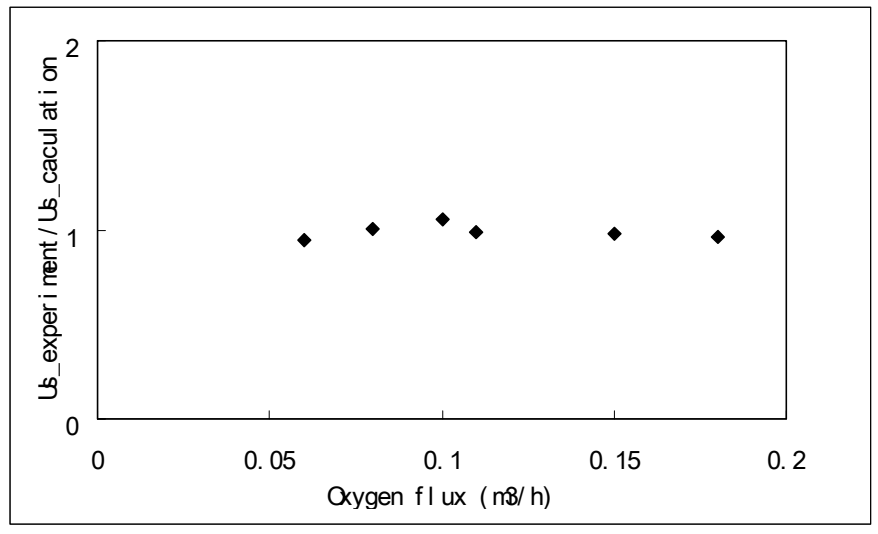

Fig. 8. Correlation of the smoldering velocity calculated from the model with the experimental measurement.

\section{CONCLUSIONS}

A series of experiments are carried out to investigate the effect of controlled oxygen supply on forward smoldering propagation of polyurethane foam located horizontally. The air supply controlled by a flux meter passes through the foam to sustain the smoldering combustion. The smoldering propagations at different air fluxes are studied. The experimental results show the oxygen supply plays a very important role in the smoldering propagation. The increasing air flux through the foam not only enhance the oxidation reaction in the reaction region and release more heats, but also increase the heat loss by convective effects. The final smoldering propagation velocity is determined by the energy balance between the two functions. From the experimental results, it is shown that the smoldering velocity increases firstly and then decreases after reaches a maximum values at air flux of $0.11 \mathrm{~m}^{3} / \mathrm{h}$. A one-dimensional theoretical model is developed by using the integral method to resolve the control equations on smoldering regions. The model is applied to calculate the smoldering propagation velocity and to compare with the experimental measurements. The good agreement between the model and the experimental results is present. 


\section{ACKNOWLEDGEMENTS}

This work was supported by the China NKBRSF (National Key Basic Research Special Funds) project, No. 2001CB409600.

\section{REFERENCES}

[1] Ohlemiller, T.J., "Modeling of Smoldering Combustion Propagation,” Progress in Energy and Combustion Science, 11, pp. 277 310, 1985.

[2] Ohlemiller, T.J., and Lucca, D.A., "An Experimental Comparison of Forward and Reverse Smolder Propagation in Permeable Fuel Beds," Combustion and Flame, 55, pp. 131 147, 1983.

[3] Dosanjh, S.S., Pagni P.J., and Fernandez-Pello, A.C., "Forced Cocurrent Smoldering Combustion," Combustion and Flame, 68, pp. 131 142, 1987.

[4] Dosanjh, S.S., and Pagni, P.J., "Forced Countercurrent Smoldering Combustion,” ASME, 1, pp. 165 173, 1987.

[5] Schult, D.A., Matkowsky, B.J., Volpert, V.A., Fernandez-Pello, A.C., "Propagation and Extinction of Forced Opposed Flow Smolder Waves," Combustion and Flame, 101, pp. 471-490, 1995.

[6] Schult, D.A., Matkowsky, B.J., Volpert, V.A., Fernandez-Pello, A.C., "Forced Forward Smolder Combustion," Combustion and Flame, 104, pp. 1 26, 1996.

[7] Torero, J.L., Fernandez-Pello, A.C., and Kitano, M., "Opposed Forced Flow Smoldering of Polyurethane Foam," Combustion Science and Technology, 91, pp. 95-117, 1993.

[8] Torero, J.L., Fernandez-Pello, A.C., "Forward Smolder of Polyurethane Foam in a Forced Air Flow," Combustion and Flame, 106, pp. 89 109, 1996.

[9] Chen Y., Delichatsios M .A. and Motevalli V., "Materials Pyrolysis Properties Part I, A Integral Model For One-dimension Transient Pyrolysis of Charring and Non-charring Materials,” Combust. Sci. and Tech., 88, pp. 309 328, 1992.

[10] Quintiere, J., and Iqbal, N., "Approximate Integral Model for the Burning Rate of a Thermoplastic-like Material,” Fire and Materials, 18, pp. 89 98, 1994.

[11] Rogers, F.E., and Ohlemiller, T.J., "Cellulosic Insulation Material em dash 2. Effect of Additives on Some Smolder Characteristics," Combustion Science and Technology, 24, pp. 139 152.

[12] Leach, S.V., Rein, G.., Ellzey, J.L., Ezekoye, O.A., and Torero, J.L., "Kinetic and Fuel Property Effects on Forward Smoldering Combustion," Combustion and Flame, 120, pp. 346 358, 2000. 